\title{
Adult persistence of head-turning asymmetry
}

A neonatal right-side preference makes a surprising romantic reappearance later in life.

A preference in humans for turning the head to the right, rather than to the left, during the final weeks of gestation and for the first six months after birth ${ }^{1,2}$ constitutes one of the earliest examples of behavioural asymmetry and is thought to influence the subsequent development of perceptual and motor preferences by increasing visual orientation to the right $\operatorname{side}^{3,4}$. Here I show that twice as many adults turn their heads to the right as to the left when kissing, indicating that this head-motor bias persists into adulthood. My finding may be linked to other forms of sidedness (for example, favouring the right foot, ear or eye) that do not become established until long after the newborn head-turning preference has disappeared ${ }^{5,6}$.

I observed kissing couples in public places (international airports, large railway stations, beaches and parks) in the United States, Germany and Turkey. The headturning behaviour of each couple was recorded for a single kiss, with only the first being counted in instances of multiple kissing. The following criteria had to be met to qualify: lip contact, face-to-face positioning, no hand-held objects (as these might induce a side preference), and an obvious head-turning direction during kissing. Subjects' ages ranged from about 13-70 years.

Of 124 kissing pairs, 80 (64.5\%) turned their heads to the right and $44(35.5 \%)$ turned to the left (Fig. 1). This roughly 2:1 ratio is significantly different from $50 \%$ $\left(\chi^{2}=5.34\right.$, d.f. $\left.=1, P<0.05\right)$. As the couples come from a biologically adult age range, this result indicates that adults have a headturning bias towards the right side, just like embryos and newborns.

Preferential use of the right foot, ear or eye is also evident as a $2: 1 \mathrm{ratio}^{7}$, which raises the possibility that these biases may be decreed by the observed head-turning preference. The incidence of right-handedness, however, is about 8:1 (ref. 8), so this particular asymmetry cannot be the result of a simple bias attributable to a right-sided head-turning tendency - the genetic origins of this trait may be different ${ }^{8}$, or cultural factors may have modified an original 2:1 pattern.

It takes two people to kiss (Fig. 2), so the bias of individuals cannot be judged from observations made on pairs. For example, what happens when a right-turner kisses a left-turner? If we assume that kissers with opposite biases could go either way with equal probability, then the individual biases should match those of the couples. For

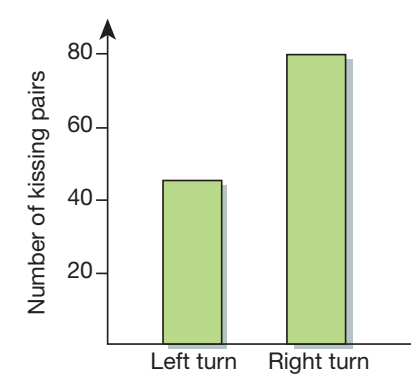

Figure 1 The number of couples who turn their heads to the right rather than to the left when kissing predominates by almost 2:1 (64.5\%: 35.5\%; $n=124$ couples).

example, if the individual bias is also $2: 1$ to the right and if couplings are random, then four of nine pairs would be right kissers, one of nine would be left-kissing, and four of nine would be mixed; if choice is random in the last group (that is, two of these four pairs are right-turning and two are leftturning), the result for the nine couples would be a right-turn kissing bias in six of them. This presumed 2:1 distribution for individuals thus predicts the observed 2:1 ratio for couples, indicating that the group bias may also reflect individual asymmetry.

In birds, a preference for turning the head to the right before hatching induces motor $^{9}$, visual ${ }^{10}$ and cognitive ${ }^{11}$ asymmetries. If a similar effect occurs in humans and an initial asymmetry in the direction of head turning stimulates various functional left-right differences ${ }^{12}$, then the head-turning bias of the newborn would have to overlap in time with the establishment of adult asymmetries. My finding that turning of the head to the right is preferred throughout adulthood suggests that, by fostering a constant bias towards the right, this mechanism may be able to induce or enhance rightsided asymmetries of perception and action. Onur Güntürkün

Biopsychologie, Fakultät für Psychologie, Ruhr-

COMMUNICATIONS ARISING

Planetary science

\section{Volcanism or aqueous alteration on Mars?}

he Mars Global Surveyor's Thermal Emission Spectrometer has identified two global spectral surface types in martian dark regions, which were initially interpreted as being of basaltic (type 1) and intermediate (type 2, basaltic andesite to andesite) volcanic composition ${ }^{1}$. Wyatt and

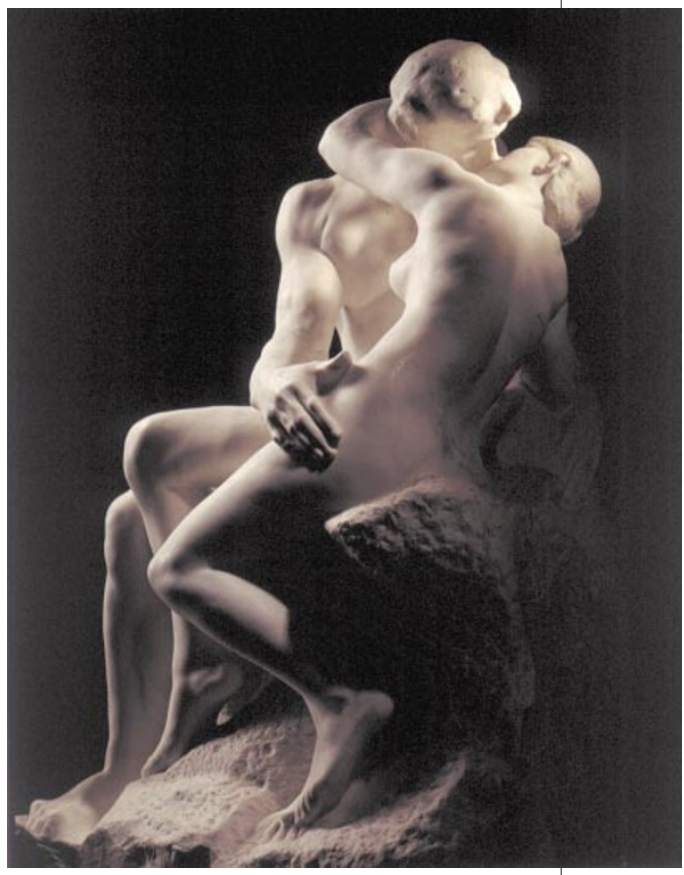

Figure 2 The Kiss: the couple in Auguste Rodin's masterpiece are turning their heads to the right to kiss each other.

Universität Bochum, 44780 Bochum, Germany e-mail:onur.guentuerkuen@ruhr-uni-bochum.de

1. Ververs, I. A. P., de Vries, J. I. P., van Geijn, H. P. \& Hopkins, B. Early Hum. Dev. 39, 83-91 (1994).

2. Konishi, Y., Mikawa, H. \& Suzuki, J. Dev. Med. Child Neurol. 28, 450-457 (1986).

3. Konishi, Y., Kuriyama, M., Mikawa, H. \& Suzuki, J. Dev. Med. Child Neurol. 29, 751-757 (1987).

4. Coryell, J. F. \& Michel, G. F. Infant Behav. Dev. 1, 245-257 (1978) 5. Michel, G. F., Sheu, C.-F. \& Brumley, M. R. Dev. Psychobiol. 40, $1-13$ (2002).

6. Gentry, V. \& Gabbard, C. J. Gen. Psychol. 122, 37-45 (1995). Reiss, M. \& Reiss, G. Percept. Mot. Skills 85, 569-574 (1997).

8. Corballis, M. C. Psychol. Rev. 104, 714-727 (1997).

9. Casey, M. B. \& Martino, C. M. Dev. Psychobiol. 37, 13-24 (2000) 10.Skiba, M., Diekamp, B. \& Güntürkün, O. Behav. Brain Res. 134 149-156 (2002).

11. Rogers, L. J. \& Andrews, R. J. (eds) Comparative Vertebrate Lateralization (Cambridge Univ. Press, Cambridge, UK, 2002).

12. Nicholls, M. E., Clode, D., Wood, S. J. \& Wood, A. G. Proc. R. Soc. Lond. B 266, 1517-1522 (1999).

Competing financial interests: declared none.

$\mathrm{McSween}^{2}$ suggest that northern-hemisphere occurrences of the type- 2 spectrum are instead representative of weathered basalt, on the basis of ambiguity in the spectral interpretation and overlap between the distribution of this material and the outline of a putative ancient ocean. Although the spectral data may be open to interpretation within the limits of current understanding, creating weathered basalt and explaining its distribution is problematic. These competing hypotheses have significantly different implications for the igneous and aqueous 
history of Mars, and it is important to continue debating the merits of each.

The model of the type- 2 spectrum with the lowest r.m.s. error includes both highsilica glasses (silica) and phyllosilicates (clay minerals), in which the silica was first interpreted as a primary igneous phase ${ }^{1}$. There is no evidence in the spectral or geological data from Mars that justifies a priori removal of silica from such models. Martian dark-region materials are primarily active sands ${ }^{1,3}$, and so are constantly abraded and are unlikely to develop or retain rinds or coatings. Infrared spectra of terrestrial sands derived from weathered basalts do not show mineralogical evidence of weathering ${ }^{4}$. Visible-spectrum and nearinfrared data have not identified abundant phyllosilicates in martian dark regions ${ }^{5}$.

Nonetheless, Wyatt and McSween exclude silica from their model, forcing it instead to include large quantities of phyllosilicates ${ }^{2}$. The increased abundance of phyllosilicate is attributed to the weathering of pyroxenes, but pyroxenes should also alter to amphibole in the presence of water, and there is no evidence of any amphibole in martian spectra ${ }^{6}$. (The lack of amphibole is not inconsistent with intermediate materials ${ }^{7}$.) K-feldspar minerals in the model are explained as the result of weathering of basalt, but a source of potassium for producing K-feldspar is not apparent in the protolith type-1 basalt, and K-feldspar is typically a product of hydrothermal, rather than ambient, aqueous alteration of basalt ${ }^{8}$. Although a reasonable fit to the data can be obtained without silica, this cannot be used to suggest that silica is not present, because it was intentionally excluded.

Columbia River basalt is the proposed martian analogue ${ }^{2}$. The mineralogy of this rock is similar to that of the type- 2 surface ${ }^{1}$, including the presence of silica on both unweathered and weathered surfaces ${ }^{2}$. However, the Columbia River basalt rock has not been subaqueously altered and is not a realistic analogue for low-temperature subaqueous alteration. Silica can be produced by hydrothermal alteration of basalt, but is unlikely to form beneath a martian ocean. The physical character of the sample (rock) is unrealistic for comparison to Mars, where active sands that are unlikely to have coatings or rinds dominate the surfaces in question.

Type-2 spectra characterize extensive areas of Mars, including the southern highlands ${ }^{1}$, and are present in vast contiguous areas up to $1,000 \mathrm{~km}$ outside and $2 \mathrm{~km}$ higher in elevation than the putative "shoreline" boundaries". Wyatt and McSween dismiss these incongruities and do not explain them ${ }^{2}$; no explanation is provided either as to how the Pathfinder landing-site analyses fit into the weatheredbasalt hypothesis ${ }^{2}$. Some interpretations of Pathfinder data identify these as andesitic

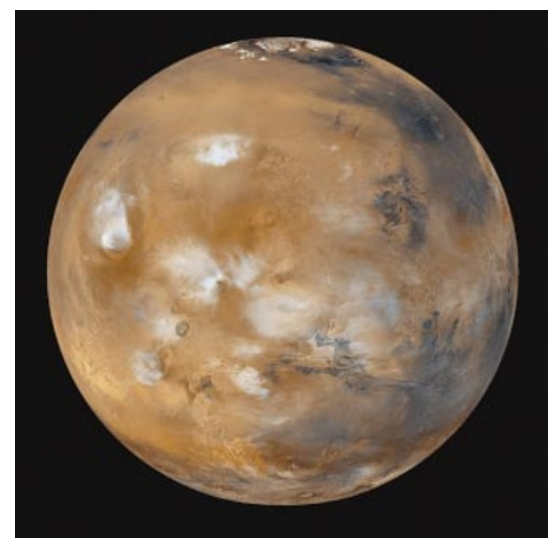

Mars, seen from the Mars Global Surveyor orbiter. The distribution of surface rock types gives clues to the planet's geological evolution.

materials ${ }^{9}$, yet they are located in a region that is contiguous with 'weathered basalt'.

In judging working hypotheses, it is common to consider the complexity of the models required to explain the data. Reconciling the global distribution of type- 2 materials with an aqueous-weathering hypothesis requires a complicated model in which all type 2 materials within the 'shoreline' are weathered basalt and in which one or more processes (other than subaqueous alteration under an ocean) produced material with identical spectra just across the shoreline and over the rest of the planet.

Terrestrial results may provide a viable mechanism for producing large quantities of intermediate volcanics ${ }^{10}$; such mechanisms have not been evaluated for Mars, making it premature to dismiss production of significant amounts of intermediate compositions. The presence of slightly weathered intermediate volcanics ${ }^{1}$ is a simpler hypothesis that explains all of the type- 2 observations without invoking the existence of an ancient ocean.

Victoria E. Hamilton*, Philip R.

\section{Christensen, Joshua L. Bandfield}

Department of Geological Sciences, Arizona State University, Tempe, Arizona 85287-6305, USA

${ }^{*}$ Present address: Hawaii Institute of Geophysics and Planetology, University of Hawaii, Honolulu, Hawaii 96826, USA

e-mail:hamilton@higp.hawaii.edu

1. Bandfield, J. L., Hamilton, V. E. \& Christensen, P. R. Science 287, 1626-1630 (2000).

2. Wyatt, M. B. \& McSween, H. Y. Jr Nature 417, 263-266 (2002).

3. Christensen, P. R. \& Moore, H. J. in Mars (eds Kieffer, H. H.,

Jakosky, B. M., Snyder, C. W. \& Matthews, M. S.) 686-729 (Univ. Arizona Press, Tucson, 1992).

4. Bandfield, J. L., Edgett, K. S. \& Christensen, P. R. J. Geophys. Res. 107, doi:10.1029/2000JE001469 (2003).

5. Bell, J. F. III in Mineral Spectroscopy: A Tribute to Roger G. Burns (eds Dyar, M. D., McCammon, C. \& Schaefer, M. W.) 359-380 (Geochem. Soc., Houston, 1996).

6. Bandfield, J. L. J. Geophys. Res. 107, 10.1029/2001JE001510 (2002). 7. Wyatt, M. B., Hamilton, V. E., McSween, H. Y., Christensen, P. R. \& Taylor, L. A., J. Geophys. Res. 106, 14711-14732 (2001). 8. Thompson, G. in Hydrothermal Processes at Seafloor Spreading Centers (eds Rona, P. A. et al.) 225-278 (Plenum, New York, 1983) 9. Foley, C. N., Economou, T. E., Dietrich, W. \& Clayton, R. N. Meteor. Planet. Sci. 35, 55-56 (2000).

10. Marsh, B. D. Geochim. Cosmochim. Acta 66, 2211-2229 (2002).
Wyatt and McSween reply - Multiple working hypotheses are prudent in the absence of definitive answers, and we suggest that there is no definitive interpretation of the surface type-2 spectrum from the Mars Global Surveyor's Thermal Emission Spectrometer (TES) $)^{1,2}$.

Demonstrations that some phyllosilicates (clay minerals) and oxidized basaltic glasses are spectrally similar to high-silica volcanic glasses ${ }^{1,3,4}$ are critical because abundant high-silica glass is an effective parameter for distinguishing basalt from andesite ${ }^{5}$ and has been used for petrological classification of TES surface type-1 and type-2 spectra. We excluded high-silica glass to examine one possible end-member of modelled mineralogies for surface type 2 . Similarly, spectral end-members of oxidized and altered glasses were not included in studies by Bandfield et al. ${ }^{2}$ and Hamilton et al. ${ }^{6}$; spectral comparison of these phases with igneous glasses was therefore not evaluated. Our preferred interpretation of type2 spectra involves a combination of igneous minerals with alteration glass and clays.

We modelled $31 \%$ (by volume) clay and $14 \% \mathrm{~K}$-feldspar for surface type 2, whereas Bandfield et al. ${ }^{2}$ modelled $15 \%$ "sheet silicate" and 6\% K-feldspar. The K-feldspar in both models 1,2 and "sheet silicate" in Bandfield et $a .^{2}$ are at or below the TES's $10-15 \%$ detectability limit. We suggested that clays and minor K-feldspar could be low-temperature aqueous-alteration products of pyroxenes and feldspars ${ }^{7}$. Pyroxenes in volcanic rocks can also alter to amphiboles in the presence of water, but such alteration is usually associated with hightemperature magmatic fluids or metamorphism. Hornblende is, however, a common phase in andesite, and the absence of modelled amphibole may be an issue in the intermediate-volcanic interpretation.

The argument of terrestrial sands derived from weathered basalts not exhibiting mineralogical evidence of weathering ${ }^{8}$ depends greatly on the extent of alteration, crystallinity, distance travelled and depositional environment. Moreover, the martian northern plains may contain a mixture of unaltered and thoroughly altered basaltic sands.

We inferred from the correlation between the locations of altered basalt on Mars and a putative northern ocean basin that lowland plains could be composed either of basalts that are partly weathered under submarine conditions, or of weathered basaltic sediments transported into this depocentre. Our Columbia River basalt sample indicated that a single rock can exhibit the type of variability seen in type-1 and type-2 materials - it did not represent 'Mars in a hand sample' and is not representative of subaqueously altered basalts. Similarly, in Bandfield et al. ${ }^{2}$ the terrestrial analogue of the type-2 surface is 